\title{
Mild Traumatic Brain Injury: Long-Term Follow-Up of Central Auditory Processing After Auditory Training
}

\author{
Ana Karina Lima Buriti and Daniela Gil \\ Department of Speech, Language and Hearing Disorders (Fonoaudiologia), Universidade Federal de São Paulo (UNIFESP), \\ São Paulo, Brazil
}

\author{
Received June 14, 2021 \\ Revised August 28, 2021 \\ Accepted September 6, 2021 \\ Address for correspondence \\ Ana Karina Lima Buriti \\ Department of Speech, Language and \\ Hearing Disorders (Fonoaudiologia), \\ Universidade Federal de São Paulo \\ (UNIFESP), 802 Botucatu St., \\ Vila Clementino, 04023-900, \\ São Paulo, Brazil \\ Tel +11 3051-5643 \\ E-mailanak_buriti@yahoo.com.br
}

Background and Objectives: Even a mild traumatic brain injury can impair the periphera and central parts of the auditory system. The objective was to compare the performance of individuals with mild traumatic brain injury in behavioral and electrophysiological central auditory tests before and after formal auditory training, and to verify the stability of these measures over time. Subjects and Methods: Ten 16- to 64-year-old individuals diagnosed with mild traumatic brain injury underwent behavioral and electrophysiological assessment of the central auditory processing in three stages: before, right after, and six months after formal auditory training. Results: Statistically significant differences were observed for speech by white noise, synthetic sentence identification, sound localization, verbal sequential memory, and duration pattern tests in the assessment six months after formal auditory training. No statistically significant differences were observed between the P300 assessments, either with tone-burst or speech stimulus, in N2 and P3 latencies, and P3 amplitude. Conclusions: The results of the behavioral assessment of the central auditory processing improved, while the P300 remained stable with both stimuli, six months after completing formal auditory training. This demonstrates that auditory training has long-term benefits for people with mild traumatic brain injury.

J Audiol Otol 2022;26(1):22-30

Keywords: Traumatic brain injury; Hearing; Auditory perception; Electrophysiology; Neuronal plasticity.

\section{Introduction}

Neural plasticity (or neuroplasticity) refers to the capacity to change neural activity. It results from neuronal responses to environmental stimuli and internal human brain stimuli, which allows the central nervous system (CNS) to adapt to physiological changes and preexisting experiences. This culminates in a learning mechanism and an increase in and development of new input connections on the neural system [1]. The plasticity of the auditory mode can be defined as the alteration of nerve cells to adjust to the immediate environmental influences, resulting in behavioral changes. The brain can reorganize the activation of neurons and neural connections that were previously at rest, due to damage or lack of stimula-

This is an Open Access article distributed under the terms of the Creative Commons Attribution Non-Commercial License (https://creativecommons.org/licenses/by-nc/4.0/) which permits unrestricted non-commercial use, distribution, and reproduction in any medium, provided the original work is properly cited. tion. These changes may take time and require specific training, or even develop through neuronal maturation without intervention [2].

In the acquired brain lesions, neuroplasticity is adaptive, and the nervous system can reorganize its structure and connections through intrinsic or extrinsic stimuli [3]. Hence, authors [4-6] reported that individuals with traumatic lesions need to receive auditory stimulation, as they observed that the perceptive processing of auditory information in the CNS and the neurobiological activity underlying this processing were altered - which is defined as central auditory processing disorder (CAPD) [7]

Many studies in the field of audiology have already documented neural plasticity in the central auditory system in individuals with CAPD $[8,9]$. Thus, the auditory system can and should be trained to improve the access to auditory information, aiming for a positive outcome not only in auditory skills but also in attention, memory, social, academic, work, and daily 
living skills. In a person with an acquired brain lesion, audiological assessment and intervention can lead them to have an improved quality of life and resume both work and academic activities performed before the injury [10].

Therefore, formal auditory training (FAT) is a neuroplasticity-based intervention approach, whose aim is to cause morphophysiological changes in the auditory pathways of the CNS and consequently in the patient's behavior after it is carried out [8]. The FAT conducted in a sound booth has been increasingly used in the auditory rehabilitation of people with auditory processing disorder $[2,11,12]$. However, few studies in the literature approach the FAT in patients with acquired neurological lesions [13-16] especially those with a mild degree, in which case, none was found in the literature.

The long-term maintenance of skills improved through the FAT is of great importance to ensure the efficiency of the intervention, indicated by either behavioral or electrophysiological assessments of the central auditory processing (CAP), especially in neurological lesions [8].

Some studies in individuals with severe traumatic brain injury $(\mathrm{TBI})$ demonstrated that the trained auditory skills remained stable a long time after the intervention had finished [17-19]. According to Batista [14], after the modification of the neural substrate and the behavioral learning, the environment and its demands reinforce the patterns learned and even keep the tendency of improvements.

We expect in this study that auditory information processing impairments caused by mild brain injury will be minimized and controlled after specific therapy intervention, with improved and stabilized results over time.

Hence, the objective of this study was to investigate the stability of the behavioral and electrophysiological measures of the CAP six months after finishing the acoustically-controlled auditory training in adults after mild TBI.

\section{Subjects and Methods}

\section{Subjects}

The sample of the study comprised ten 16- to 64-year-old individuals who had suffered a brain lesion 4 to 12 months before. They had a medical diagnosis of mild closed TBI, considering the Glasgow coma scale when they were admitted to the hospital (Table 1). They had no previous or current complaints of affections in the auditory system; auditory thresholds lower than or equal to $25 \mathrm{~dB}$ HL between $250 \mathrm{~Hz}$ and 4,000 $\mathrm{Hz}$, bilaterally [20]; tympanometry type A curve, bilaterally [21]; and absence of diagnosed psychiatric alterations, such as depression, anxiety, bipolar and schizophrenic disorders.

\section{Methods and analysis of audiological tests}

The procedures used in this study were the behavioral and electrophysiological assessments of the CAP. They were conducted at three different moments: before the FAT, right after the last FAT session, and six months after finishing the FAT.

Behavioral assessment of the CAP comprised 10 tests, namely: sound localization test (SLT), sequential memory test for

Table 1. Demographic data of the study participants diagnosed with mild traumatic brain injury

\begin{tabular}{|c|c|c|c|c|c|c|c|c|}
\hline$N$ & Age & Sex & $\begin{array}{l}\text { Educational } \\
\text { attainment }\end{array}$ & Medical diagnosis & $\begin{array}{l}\text { Lesion } \\
\text { side }\end{array}$ & Surgery & Hospitalization & Medication \\
\hline 1 & 51 & $M$ & $\begin{array}{l}\text { High school, } \\
\text { not completed }\end{array}$ & Chronic subdural hematoma & Left & Yes & 3 days & No \\
\hline 2 & 64 & $M$ & High school graduate & $\begin{array}{l}\text { Frontal and parietal } \\
\text { intraparenchymal hematoma }\end{array}$ & Left & No & 3 days & Sertraline \\
\hline 3 & 58 & M & $\begin{array}{l}\text { Middle school, } \\
\text { not completed }\end{array}$ & Acute subdural hematoma & Left & No & 4 days & No \\
\hline 4 & 32 & $\mathrm{~F}$ & $\begin{array}{l}\text { Middle school, } \\
\text { not completed }\end{array}$ & $\begin{array}{l}\text { Medial frontal contusion+temporal } \\
\text { contusion }\end{array}$ & Bilateral & No & 1 day & No \\
\hline 5 & 16 & $M$ & $\begin{array}{l}\text { High school, } \\
\text { not completed }\end{array}$ & Frontal extradural empyema & Left & Yes & $\begin{array}{l}2 \text { months }-3 \text { days } \\
\text { ICU }\end{array}$ & No \\
\hline 6 & 64 & $\mathrm{~F}$ & Bachelor's degree & Frontal contusion & Right & No & 3 days & Sertraline \\
\hline 7 & 28 & $M$ & High school graduate & Parietal extradural hematoma & Right & Yes & 4 days & No \\
\hline 8 & 21 & M & High school graduate & Diffuse contusion & Bilateral & No & No & Fluoxetine \\
\hline 9 & 55 & $M$ & $\begin{array}{l}\text { Middle school, } \\
\text { not completed }\end{array}$ & $\begin{array}{l}\text { Temporal extradural hematoma+ } \\
\text { acute epidural hematoma+ } \\
\text { frontotemporal laminar acute } \\
\text { subdural hematoma }\end{array}$ & Bilateral & Yes & 5 days & No \\
\hline 10 & 56 & $M$ & High school graduate & Chronic subdural hematoma & Bilateral & Yes & 3 days & No \\
\hline
\end{tabular}


verbal sounds (SMTV) and sequential memory test for nonverbal sounds (SMTNV), speech by white noise (SWN), synthetic sentence identification (SSI) with an ipsilateral competing message, dichotic staggered spondaic word, duration pattern test (DPT), dichotic consonant-vowel test (DCVT), random gap detection test (RGDT), masking-level difference (MLD). The audiometer used was the model GSI-61, manufactured by Grason-Stadler (Eden Prairie, MN, USA), with TDH50P earphones (Grason-Stadler). The analysis criteria used in each test were those proposed by Pereira [22], as shown in Table 2.

For the electrophysiological assessment, the individuals were seated in a comfortable reclining chair in an acoustic, electrically treated room.

For the cognitive potential (P300) research, two stimuli were used: tone-burst and speech. To obtain the potentials, the stimulus was presented monaurally at $75 \mathrm{~dB} \mathrm{HL}$, at the frequencies of $1,000 \mathrm{~Hz}$ (frequent stimulus) and 2,000 Hz (rare stimulus), lasting $50 \mathrm{~ms}$, following the rare-frequent paradigm. To obtain the potential using the speech stimulus, the syllables used were "ba" (frequent stimulus) and "da" (rare stimulus). For both stimuli (tone-burst and speech), the person was instructed to count the number of times the rare stimulus appeared, telling the total number at the end of the pick-up. The N2 and P3 latencies and P3 amplitude were registered and analyzed, in a new tracing, resulting from subtracting the rare tracing from the frequent one.

The potential analysis with tone-burst stimulus considered the normality values for $\mathrm{N} 2$ and $\mathrm{P} 3$ latencies proposed by McPherson [23]. As for the potential analysis with speech stimulus, the reference value used was the one proposed by Perez, et al. [24].

After these two assessments, the individuals were submitted to 10 weekly individual FAT sessions, lasting 50 minutes each, following the FAT activity schedule in each session (Table 3). In each session, the activities proposed were recognition and discrimination of verbal and nonverbal sounds, temporal ordering, figure-ground for verbal and nonverbal sounds, and auditory closure. The tasks and signal-to-noise ratio were progressively organized, according to the level of complexity. To move to the next stage of the auditory training, the person had to present at least $70 \%$ of correct answers [8].

\section{Statistical analysis}

The statistical calculations of the research data were obtained through the IBM SPSS program, version 25 (IBM Corp., Armonk, NY, USA). To evaluate the difference between the three assessments (before, right after, and six months after the FAT), the F-test (ANOVA) was used for repeated measures; Student's t-test for null correlation hypothesis; Wilcoxon test for rejection of the hypothesis; and in case of significant difference, Bonferroni or least significant difference multiple comparison

Table 2. Description of the normal values for the central auditory processing tests

\begin{tabular}{|c|c|}
\hline Test & Normal values \\
\hline Sound localization test & $4 / 5$ correct answers (as long as $R$ and $L$ do not fail) \\
\hline Sequential memory test for verbal sounds & $2 / 3$ correct answers \\
\hline Sequential memory test for nonverbal sounds & $2 / 3$ correct answers \\
\hline Speech by white noise & $\geq 70 \%$ and SRPI - SRPIWN $<20 \%$ \\
\hline $\begin{array}{l}\text { Synthetic sentence identification with an ipsilateral } \\
\text { competing message }\end{array}$ & $\operatorname{ICM}(-15) \geq 60 \%$ correct answers \\
\hline Duration pattern test & $>12$ years old: $\geq 83 \%$ (23) correct answers; naming = humming (Musiek) \\
\hline Dichotic consonant-vowel test & $\begin{array}{l}\geq 12 \text { years old: } \geq 19 \text { correct answers (right ear advantage), errors } \leq 5 \\
\text { Left-handed: } \geq 19 \text { right answers (REA or LEA), errors } \leq 5\end{array}$ \\
\hline Dichotic staggered spondaic word & $\begin{array}{l}>9 \text { years old: } \\
\text { CR: } \geq 90 \% \text { correct answers, CL: } \geq 90 \% \text { correct answers } \\
\text { AE: }[-4 \text { to }+4], \text { OE: }[-3 \text { to }+3] \\
\text { Inversions: } \leq 1 \text {, Type A: } \leq 3 \\
\text { Degree classification } \\
\text { Normal: } \geq 90 \% \text { correct answers } / \text { mild: } 80 \%-89 \% \text { correct answers/ } \\
\text { moderate: } 60 \%-79 \% \text { correct answers } / \text { severe: } 40 \%-59 \% \text { correct } \\
\text { answers }\end{array}$ \\
\hline Random gap detection test & $\geq 7$ years old: 2 to $10 \mathrm{~ms}$ \\
\hline Masking-level difference & $\geq 12$ years old: $\geq 10 \mathrm{~dB}$ \\
\hline
\end{tabular}

R, right; L, left; SRPI, speech recognition percentage index; SRPIWN, speech recognition percentage index by white noise; ICM, ipsilateral competing message; $R E A$, right ear advantage; LEA, left ear advantage; $C R$, competing right; $C L$, Competing left; $A E$, auditory effect; OE, order effect; ms, milliseconds 
Table 3. Activities carried out in each formal auditory training session

\begin{tabular}{|c|c|c|c|c|}
\hline Sessions & Auditory skills & Stimuli presentation & Ear trained & SNR $(\mathrm{dB})$ \\
\hline \multirow[t]{2}{*}{ lst session } & Figure-ground & Monotic task & RE and LE & 0 and $-40(\mathrm{CCM})$ \\
\hline & & & & +10 to -20 (ICM) \\
\hline \multirow[t]{2}{*}{ 2nd session } & Figure-ground & Dichotic task (directed hearing) & RE & +10 to -30 \\
\hline & & & LE & $0,-20,-40$ \\
\hline \multirow[t]{2}{*}{ 3rd session } & Figure-ground & Dichotic task (directed hearing) & LE & +10 to -30 \\
\hline & & & RE & $0,-20,-40$ \\
\hline \multirow[t]{2}{*}{ 4th session } & Figure-ground & Dichotic task (binaural integration) & $R E+L E$ & 0 \\
\hline & Auditory closure & Monotic task & RE & +10 to -5 \\
\hline \multirow[t]{3}{*}{ 5th session } & Auditory closure & Monotic task & LE & +10 to -5 \\
\hline & & Monotic task & RE and LE & +10 to -10 \\
\hline & & & & +5 to -5 \\
\hline 6th session & Temporal processing & Dichotic task & $R E+L E$ & 0 \\
\hline 7th session & Temporal processing & Dichotic task & $R E+L E$ & 0 \\
\hline 8th session & Temporal processing & Dichotic task & $R E+L E$ & 0 \\
\hline 9th session & Temporal processing & Dichotic task & $R E+L E$ & 0 \\
\hline \multirow[t]{2}{*}{ 10th session } & Figure-ground & Dichotic task (directed hearing) & RE and LE & +40 to -10 \\
\hline & & Dichotic task (binaural integration) & $R E+L E$ & 0 \\
\hline
\end{tabular}

tests were used. The margin of error used in the decision of the statistical tests was 0.05 .

\section{Ethics committee approval and informed consent}

This is a descriptive, longitudinal, cross-sectional study, conducted in the clinical audiology and neuroaudiology outpatient center in the course on hearing disorders in the department of speech-language-hearing of the Universidade Federal de São Paulo (UNIFESP). It was approved by the Research Ethics Committee of the Universidade Federal de São Paulo (UNIFESP), under number 1.844.535. All the individualsor the adult responsible for them - signed the informed consent and/or assent form before the study began.

\section{Results}

The results of this study were based on the assessments of 10 individuals - two females and eight males, aged from 16 to 64 years, who had suffered mild TBI - before and after the FAT. Two of these individuals were not assessed six months after finishing the FAT: one for incompatible schedules and the other for family health issues. Hence, eight individuals were assessed six months after the FAT.

The results of the behavioral assessment of the CAP are presented in Table 4, considering the three assessment moments: before the FAT, right after finishing the FAT, and six months after finishing the FAT. It is worth mentioning that all subjects showed abnormal results in at least one of the behavioral procedures performed.
There was statistically significant difference in the SWN in the right ( $p=0.022)$ and left ear $(p=0.019)$; in the SSI in the right $(p=0.001)$ and left ear (0.009); in the SLT ( $p=0.021)$; SMTV $(p=0.010)$; and DPT ( $p=0.024)$ in the assessments six months after the FAT when compared to the assessments before and after the FAT (Table 4). In the other tests, it was observed that the means of the results of the reassessment six months after the FAT remained stable, comparing them with the assessment right after the FAT.

In the assessment after six months, despite the stability of the results of some tests, there was mostly a tendency to better results in the SWN, DCVT-errors, SMTV, SMTNV, and RGDT.

The quantitative reduction of altered individuals in all reassessment tests six months after the FAT is shown in Table 5, in comparison with the post-FAT assessment, except for the DPT and MLD.

For the tone-burst stimulus, no statistically significant difference was observed in the N2 and P3 latencies and P3 amplitude between the assessment before, right after, and six months after the FAT (Table 6).

For the speech stimulus, no statistically significant difference was observed either in the N2 and P3 latencies and P3 amplitude between the assessment before, right after, and six months after the FAT (Table 6).

\section{Discussion}

CAPD was identified in subjects after mild TBI using behavioral and electrophysiological measures. Subjects were 
Table 4. Behavioral assessment of the central auditory processing before, right after, and six months after the formal auditory training, considering the tests used and the ear

\begin{tabular}{|c|c|c|c|c|c|}
\hline Behavioral tests & Ear & Before & Right after & After six months & p-value \\
\hline SWN & Right & $67.60 \pm 16.91(70.00)^{A)}$ & $76.80 \pm 10.29(80.00)^{B)}$ & $83.50 \pm 6.91(86.00)^{B)}$ & $p=0.022^{* \dagger}$ \\
\hline \multirow[t]{2}{*}{ (\% correct answers) } & Left & $65.60 \pm 7.11(64.00)^{A)}$ & $74.40 \pm 10.36(74.00)^{\mathrm{AB})}$ & $81.50 \pm 7.07(82.00)^{\mathrm{B})}$ & $p=0.019^{* *}$ \\
\hline & $p$-value & $p=0.678$ & $p=0.329$ & $p=0.381^{\|}$ & \\
\hline SSI-ICM (SNR: 15) & Right & $63.00 \pm 17.67(65.00)^{\mathrm{A})}$ & $75.00 \pm 15.09(70.00)^{\mathrm{B})}$ & $82.50 \pm 11.65(85.00)^{\mathrm{B})}$ & $p=0.001^{*^{\dagger}}$ \\
\hline \multirow[t]{2}{*}{ (\% correct answers) } & Left & $61.00 \pm 17.29(70.00)^{A)}$ & $71.00 \pm 18.53(80.00)^{B)}$ & $78.75 \pm 8.35(80.00)^{\mathrm{B})}$ & $p=0.00 *^{*}$ \\
\hline & p-value & $p=0.678^{\|}$ & $p=0.399^{\|}$ & $p=0.504^{\|}$ & \\
\hline SSW & Right & $83.00 \pm 17.11(88.75)$ & $89.75 \pm 12.44$ (93.75) & $89.38 \pm 11.86(92.50)$ & $p=0.094^{\S}$ \\
\hline \multirow[t]{2}{*}{ (\% correct answers) } & Left & $81.75 \pm 13.02(85.00)$ & $85.00 \pm 16.41(90.00)$ & $86.25 \pm 17.06(95.00)$ & $p=0.081^{\S}$ \\
\hline & p-value & $p=0.435^{\natural}$ & $p=0.038^{*} \|$ & $p=0.286^{\|}$ & \\
\hline DCVT & Right & $10.40 \pm 3.44(10.50)$ & $12.10 \pm 2.96(11.50)$ & $11.63 \pm 2.33(11.00)$ & $p=0.568^{\S}$ \\
\hline \multirow[t]{2}{*}{ (correct answers) } & Left & $8.00 \pm 3.20(7.50)$ & $6.50 \pm 2.55(6.50)$ & $8.13 \pm 2.47(9.00)$ & $p=0.258^{\S}$ \\
\hline & p-value & $p=0.217^{\|}$ & $p=0.009 * \|$ & $p=0.070$ & \\
\hline DCVT (number of errors) & & $5.60 \pm 3.37(4.00)$ & $5.20 \pm 1.40(5.00)$ & $4.25 \pm 1.28(4.50)$ & $p=0.576^{\S}$ \\
\hline SLT (\% correct answers) & & $\left.68.00 \pm 19.32(80.00)^{A}\right)$ & $82.00 \pm 19.89(80.00)^{B)}$ & $85.00 \pm 20.70(90.00)^{\mathrm{B})}$ & $p=0.021^{* \dagger}$ \\
\hline SMTV (\% correct answers) & & $50.00 \pm 36.00(50.00)^{A)}$ & $73.33 \pm 21.08(66.66)^{A B)}$ & $79.16 \pm 17.26(66.66)^{\mathrm{B})}$ & $p=0.010^{* *}$ \\
\hline SMTNV & & $63.33 \pm 36.68(66.66)$ & $73.33 \pm 34.43(83.33)$ & $79.16 \pm 24.80(83.33)$ & $p=0.205^{\S}$ \\
\hline (\% correct answers) & & & & & \\
\hline RGDT (ms) & & $10.25 \pm 6.67(8.13)$ & $5.60 \pm 2.77(4.50)$ & $4.37 \pm 1.25(4.25)$ & $p=0.057^{\S}$ \\
\hline DPT (\% correct answers) & & $62.53 \pm 26.85(64.97)^{\mathrm{A})}$ & $\left.79.32 \pm 24.40(88.33)^{A B}\right)$ & $88.75 \pm 14.36(93.35)^{\mathrm{B})}$ & $p=0.024^{*+}$ \\
\hline $\operatorname{MLD}(\mathrm{dB})$ & & $12.80 \pm 3.43(12.00)$ & $12.20 \pm 2.57(12.00)$ & $11.00 \pm 3.55(10.00)$ & $p=0.382^{\S}$ \\
\hline
\end{tabular}

Data are presented as mean \pm standard deviation (median). Different letters $A$ and $B$ means that there was a significant difference between the corresponding assessments. *significant difference at the level of $0.05{ }^{\dagger}{ }^{\dagger}$ through the F-test (ANOVA) for repeated measures with the least significant difference (LSD) multiple comparisons; " through the F-test (ANOVA) for repeated measures with Bonferroni multiple comparisons; " through the F-test (ANOVA) for repeated measures; "through Student's paired t-test; " through Wilcoxon paired test. SWN, speech by white noise test; SSIICM, synthetic sentence identification with an ipsilateral competing message; SNR, signal-to-noise ratio; SSW, dichotic staggered spondaic word; DCVT, dichotic consonant-vowel test; SLT, sound localization test; SMTV, sequential memory test for verbal sounds; SMTNV, sequential memory test for nonverbal sounds; RGDT, random gap detection test; DPT, duration pattern test; MLD, masking-level difference

enrolled in a FAT program and reevaluated twice after the intervention: right after and six months after the last training session. Performance was better in behavioral measures after the training program.

In the assessment conducted in this study six months after finishing the FAT, better quantitative and qualitative results were observed in some of the procedures, as well as stability of the results of others. This demonstrates modifications in the plasticity of the CNS, with better responses in all behavioral assessment tests, and no worse performance in the auditory skills and P3 latencies of the cognitive potentials, in the follow-up assessment six months after the FAT.

Usually, mild TBI does not have severe sequelae perceived by the individual. Either with or without surgical intervention, the patients in this study had a quick recovery. Four months after the TBI, they underwent behavioral and electrophysiological assessments. In this sense, the individual can recover quickly and resume their activities of work and daily living oftentimes without recognizing the difficulties resulting from brain trauma. When a person suffers a TBI, even without apparent sequelae, the central auditory nervous system can be affected - which requires assessment and rehabilitation. This study proves to be original, as there are few studies with longterm follow-up after stimulation, aiming to characterize the auditory performance of subjects after mild TBI, comparing the results in behavioral and electrophysiological tests before and after FAT, whether there was stability in the responses obtained after the therapeutic intervention, especially in the mild cases.

It is known that auditory skills training can stimulate neuroplasticity, and in many cases, the maintenance of the behavioral improvements depends on continuous exposure to therapy [3]. Thus, Murphy, et al. [25] demonstrated the efficiency of the auditory training for the stimulation of neural plasticity through the improvement of the auditory skills in the individual with TBI.

In the descriptive analysis of the CAP reassessment six months after the FAT, comparing the assessments before and after it (Table 4), a statistically significant difference was observed in the comparison of the means of the SWN and SSI tests in both ears, SLT, SMTV, SMTNV, and DPT. Hence, it demonstrates that six months after the FAT there was a long- 
Table 5. Qualitative analysis of the behavioral assessment of the central auditory processing before, right after, and six months after the formal auditory training by test

\begin{tabular}{|c|c|c|c|c|c|c|}
\hline \multirow{2}{*}{ Behavioral tests } & \multicolumn{2}{|c|}{ Before $(n=10)$} & \multicolumn{2}{|c|}{ Right after $(n=10)$} & \multicolumn{2}{|c|}{ After six months $(n=8)$} \\
\hline & Normal & Altered & Normal & Altered & Normal & Altered \\
\hline SWN & $1(10.0)$ & $9(90.0)$ & $6(60.0)$ & $4(40.0)$ & $7(87.5)$ & $1(12.5)$ \\
\hline SSI-ICM (SNR: 15) & $6(60.0)$ & $4(40.0)$ & $8(80.0)$ & $2(20.0)$ & $8(100.0)$ & $0(0.0)$ \\
\hline SSW & $4(40.0)$ & $6(60.0)$ & $6(60.0)$ & $4(40.0)$ & $6(75.0)$ & $2(25.0)$ \\
\hline DCVT (errors) & $6(60.0)$ & $4(40.0)$ & $6(60.0)$ & $4(40.0)$ & 7 (87.5) & $1(12.5)$ \\
\hline SLT & $7(70.0)$ & $3(30.0)$ & $8(80.0)$ & $2(20.0)$ & 7 (87.5) & $1(12.5)$ \\
\hline SMTV & $5(50.0)$ & $5(50.0)$ & $9(90.0)$ & $1(10.0)$ & $8(100.0)$ & $0(0.0)$ \\
\hline SMTNV & $6(60.0)$ & $4(40.0)$ & $8(80.0)$ & $2(20.0)$ & 7 (87.5) & $1(12.5)$ \\
\hline RGDT & $6(60.0)$ & $4(40.0)$ & $9(90.0)$ & $1(10.0)$ & $8(100.0)$ & $0(0.0)$ \\
\hline DPT & $2(20.0)$ & $8(80.0)$ & $8(80.0)$ & $2(20.0)$ & $6(75.0)$ & $2(25.0)$ \\
\hline MLD & 9 (90.0) & $1(10.0)$ & 9 (90.0) & $1(10.0)$ & $6(75.0)$ & $2(25.0)$ \\
\hline
\end{tabular}

Data are presented as $n$ (\%). SWN, speech by white noise; SSI-ICM, synthetic sentence identification with an ipsilateral competing message; SNR, signal-to-noise ratio; SSW, dichotic staggered spondaic word; DCVT, dichotic consonant-vowel test; SLT, sound localization test; SMTV, sequential memory test for verbal sounds; SMTNV, sequential memory test for nonverbal sounds; RGDT, random gap detection test; DPT, duration pattern test; MLD, masking-level difference

Table 6. Characterization of the cognitive potential (P300) with the tone-burst and speech stimuli before, right after, and six months after the formal auditory test by ear

\begin{tabular}{|c|c|c|c|c|c|}
\hline Type of stimulus & Ear & Before & Right after & After six months & p-value \\
\hline \multicolumn{6}{|l|}{ Tone-burst } \\
\hline \multirow[t]{3}{*}{ N2 latency (ms) } & Right & $242.10 \pm 33.11(234.00)$ & $250.60 \pm 48.28(245.50)$ & $238.00 \pm 26.58(234.50)$ & $p=0.471^{\dagger}$ \\
\hline & Left & $215.13 \pm 20.16(210.50)$ & $229.10 \pm 21.88(229.00)$ & $212.63 \pm 27.27(218.00)$ & $p=0.737^{\dagger}$ \\
\hline & $p$-value & $p=0.107^{\S}$ & $p=0.130^{\phi}$ & $p=0.093^{\phi}$ & \\
\hline \multirow[t]{3}{*}{ P3 latency (ms) } & Right & $320.10 \pm 23.58(309.00)$ & $323.30 \pm 34.49(311.00)$ & $303.63 \pm 38.98(314.50)$ & $p=0.394^{\dagger}$ \\
\hline & Left & $300.50 \pm 32.84(294.00)$ & $299.40 \pm 34.77(295.50)$ & $290.63 \pm 37.06(276.00)$ & $p=0.566^{\dagger}$ \\
\hline & $p$-value & $p=0.097^{\dagger}$ & $p=0.006^{*{ }^{*}}$ & $p=0.346^{\dagger}$ & \\
\hline \multirow[t]{3}{*}{ P3 amplitude ( $\mu \mathrm{V})$} & Right & $5.08 \pm 2.57(6.05)$ & $5.29 \pm 2.76(5.34)$ & $5.28 \pm 1.13(5.51)$ & $p=0.934^{\dagger}$ \\
\hline & Left & $5.61 \pm 2.19(5.31)$ & $5.88 \pm 2.31(5.69)$ & $5.54 \pm 1.77(4.74)$ & $p=0.846^{\dagger}$ \\
\hline & $p$-value & $p=0.850^{*}$ & $p=0.523^{\dagger}$ & $p=0.346^{\dagger}$ & \\
\hline \multicolumn{6}{|l|}{ Speech } \\
\hline \multirow[t]{3}{*}{ N2 latency (ms) } & Right & $224.33 \pm 17.99(221.00)$ & $216.30 \pm 7.20(216.50)$ & $222.50 \pm 14.44(218.00)$ & $p=0.440^{\dagger}$ \\
\hline & Left & $226.70 \pm 27.69(215.50)$ & $220.90 \pm 32.37(215.00)$ & $214.50 \pm 18.46(219.00)$ & $p=0.059^{\dagger}$ \\
\hline & $p$-value & $p=0.853^{\dagger}$ & $p=0.859^{\S}$ & $p=0.474^{\dagger}$ & \\
\hline \multirow[t]{3}{*}{ P3 latency (ms) } & Right & $303.78 \pm 37.98(293.00)$ & $296.00 \pm 34.50(294.00)$ & $287.38 \pm 31.68(275.00)$ & $p=0.461^{\dagger}$ \\
\hline & Left & $291.30 \pm 30.15(292.00)$ & $301.80 \pm 41.38(288.50)$ & $281.25 \pm 20.17(284.00)$ & $p=0.150^{\dagger}$ \\
\hline & $p$-value & $p=0.237^{\dagger}$ & $p=0.240^{中}$ & $p=0.449^{\dagger}$ & \\
\hline \multirow[t]{3}{*}{ P3 amplitude $(\mu \mathrm{V})$} & Right & $8.00 \pm 4.59(6.33)$ & $8.64 \pm 2.80(8.91)$ & $8.47 \pm 2.97(8.18)$ & $p=0.797^{\dagger}$ \\
\hline & Left & $5.71 \pm 2.82(4.90)$ & $8.08 \pm 2.36(8.73)$ & $7.48 \pm 2.49(8.36)$ & $p=0.062^{\dagger}$ \\
\hline & $p$-value & $p=0.044^{*{ }^{*}}$ & $p=0.494^{*}$ & $p=0.245^{\phi}$ & \\
\hline
\end{tabular}

Data are presented as mean \pm standard deviation (median). *significant difference at the level of 0.05 ; ${ }^{\dagger}$ through the F-test (ANOVA) for repeated measures; " through Student's paired t-test; ${ }^{\S}$ through Wilcoxon paired test

term improvement in the auditory skills of auditory closure, figure-ground for verbal sounds in monotic hearing, sound source localization, verbal sounds sequential organization, and temporal processing regarding the duration of the sounds.

It should be highlighted that the DCVT (amount of errors), SMTNV, RGDT, and MLD tests presented better mean results in the reassessment six months after the auditory training when compared to the assessment right after it. The SSW and DCVT test (number of correct answers) maintained stable results when compared to the post-FAT assessment, and improved, as previously stated, in relation to the pre-intervention assessment. Therefore, it is demonstrated that the skills already improved in the FAT further improved during the follow-up, whereas some remained stable (i.e., no worsening was observed in the performance of any of the tests used, evidencing the efficiency of the therapeutic approach). This reinforc- 
es the concept of neural plasticity, which states that when the neural substrate is modified, the environment itself reinforces the learned pattern [12].

It was observed in the DCVT that the right ear maintained its advantage in the reassessment six months after the FAT. That had already been observed in the assessments before and right after the FAT, reinforcing the left hemisphere dominance for linguistic sounds in this group of patients.

In the qualitative analysis of the behavioral tests (Table 5), it was observed in the reassessment six months after the FAT that few individuals maintained alterations in any skill; a $100 \%$ normality was verified in the SSI, SMTV, and RGDT tests. These changes and maintenance of results six months after the FAT reflect the capacity of a person with mild TBI to modify behaviors due to neuroplasticity after auditory stimulation and remain stable through time. Furthermore, they reinforce the importance of a long-term follow-up in these individuals to make new therapeutic decisions.

Therefore, the CAP results in the reassessment six months after the FAT demonstrated that the long-term follow-up was important to reveal the stability and improvements of the auditory skills after the FAT in individuals with mild TBI. This shows the capacity of the brain to be modified with the therapeutic stimulus and maintain it with the environmental stimulus. Hence, it corroborates the study by Murphy, et al. [25], who reassessed individuals with moderate TBI four months after the FAT and observed that the performance remained stable in the skills of figure-ground for verbal sounds and auditory closure.

Other studies [19,26,27] also described the efficiency of the auditory training and the maintenance of the trained auditory skills after six months or more, proving the long-term efficiency of the training in individuals with CAPD.

In the descriptive analysis of the cognitive potential register (Table 6) six months after the FAT, despite the P3 latency presenting a decrease, it was not statistically significant either for tone-burst or speech stimuli. Hence, the results were stable.

It is important to highlight that most of the CAP test results in the assessment six months after the intervention involved verbal stimuli. This corroborates the cognitive potential result (P300), which had lower P3 latency for the speech stimulus in both ears, between the assessments before and after the FAT, with symmetry between the ears in the follow-up assessment. This result demonstrated that a shorter time was required to process acoustic information with linguistic symbols (speech) than tonal stimuli (Table 6), in individuals with mild TBI. This reveals a neurophysiological change in the CNS in the long run.

Regarding the N2 latency, no statistically significant difference was observed between the assessments for both stimuli.
Nevertheless, a decrease in N2 latency in both ears was noticed with tone-burst stimulus and a decrease in N2 latency in the left ear for speech stimulus, in the assessment six months after the FAT (Table 6). This preattentional moment represented by the N2 wave for the speech stimulus may mean that the individuals in this study were attentive at the beginning of the stimulus, which is a preconscious moment from the environmental to the speech stimulus. Then, as the cognitive activity (P300) began, the perception, discrimination, and sound stimulus recognition improved, which was observed in the decreased P3 wave latency in the assessment six months after the therapeutic intervention.

In summary, it was noticed in this study that verbal sounds were more easily discriminated after the FAT, as observed by the increase in P3 amplitude for speech stimuli. Hence, it can be stated that there was neural plasticity, which was also observed in the behavioral tests that showed improvement in the performance of attention, memory, and selective attention skills. It is important to highlight that there was a statistically significant difference between the ears in P3 amplitude and that in the post-FAT assessment the ears had symmetrical results (Table 6). Also, the P3 amplitude remained stable in the assessment six months after the FAT, demonstrating a maintained number of neural sources that the attentional system mobilized to perform the task.

Given that, when observing these results, it can be stated that the FAT helped the individuals with mild TBI to overcome their difficulties in processing acoustic information. Hence, they attained a better quality of life and improved longterm cognitive, memory, and attention skills, as stated by the subjects during the follow-up period. Similarly, Figueiredo, et al. [17] verified that the P300 results remained stable in individuals with severe TBI one year after the FAT. This demonstrated not only the maintenance of the neurophysiological changes achieved after the auditory training but also long-term improvements.

Duncan, et al. [28] assessed the cognitive potential two years after the TBI and observed delayed P3 latency and decreased P3 amplitude. The individuals did not undergo therapeutic intervention, although they were stimulated by the environment. Thus, the P300 had worse results or remained altered in the long run, which suggests cognitive and information processing impairment, reinforcing the importance of enrolling these patients in intervention programs.

As for the individuals in this study who were submitted to an auditory stimulation through the FAT and were reassessed six months after the training, the P3 amplitude remained stable in both eliciting stimuli. Regarding the differences between the ears, for the P3 latency with tone-burst, a neural synchrony 
balance was observed six months after the FAT (Table 6).

According to Polich, et al. [29], the reliability of long-term stability of the P300 component reflects in habituation or dishabituation of certain processes in the CNS. Matas, et al. [30] demonstrated great reliability for P3 wave stability after three months in normal adults. Hence, it is a recommended procedure for therapeutic monitoring.

There is no consensus in the literature regarding the relationship between the degree of severity in TBI and the performance in the electrophysiological assessment before and after the intervention. Murphy, et al. [25] demonstrated morphological deterioration and $\mathrm{P} 3$ amplitude reduction in moderate TBIs, highlighting the nonstability of the results in assessments 4 months after auditory training. Godoy and Gil [18] showed maintained performance in the behavioral tests and improved electrophysiological results after FAT, evidenced with the P3 decreased latency and increased amplitude in both ears, in severe TBIs.

Ledwidge and Molfese [31] demonstrated that there are long-term cognitive impairments associated with past concussions. Thus, Segalowitz, et al. [32] showed that individuals who suffered mild TBI, even with excellent behavioral recovery, can have subtle deficits in the attention processes, which can last for a long time after the brain lesion. These require attention regarding diagnosis and rehabilitation. Hence, it can be reflected in the need for individuals with TBI to undergo rehabilitation of the auditory skills and continue the therapeutic follow-up and monitoring of the results of long-term auditory and cognitive skills.

Hence, this study showed the importance of not only assessing the patient and conducting a therapeutic intervention program but also following up with the individual to observe the stability of the results obtained after the FAT. Thus, these individuals are given a better quality of life - who are mostly young and need to resume their academic and professional activities.

It is suggested that other studies assessing the central auditory pathway be conducted with long-term follow-up after the FAT. Further studies must make use of larger samples with the therapeutic intervention of the CAP. Hence, greater scientific evidence would be provided for the findings obtained in this study.

This study concluded that the improvement in the results of the behavioral assessments of the CAP and the stability of the P300 in tone-burst and speech stimuli six months after finishing the FAT demonstrated that the training program helped the individuals with mild TBI reduce the difficulty in processing acoustic information. This resulted in improved long-term cognitive, memory, and attention skills.

\section{Acknowledgments}

Gratitude is extended to my colleague doctor responsible for the neurotrauma outpatient center of the university hospital) for referring the patients for this study. Also, to my colleague doctor for the discerning review of the auditory electrophysiological tracings.

Coordination for the Improvement of Higher Education Personnel (CAPES-Brazil), a foundation of the Brazilian Ministry of Education (MEC).

\section{Conflicts of interest}

The authors have no financial conflicts of interest.

\section{Author Contributions}

Data curation: Ana Karina Lima Buriti. Formal analysis: Ana Karina Lima Buriti. Funding acquisition: Ana Karina Lima Buriti. Investigation: Ana Karina Lima Buriti. Methodology: Ana Karina Lima Buriti. Project administration: Ana Karina Lima Buriti. Resources: Daniela Gil. Software: Daniela Gil. Supervision: Daniela Gil. Validation: Daniela Gil. Visualization: Daniela Gil. Writingoriginal draft \& editing: Ana Karina Lima Buriti. Writing — review: Daniela Gil. Approval of final manuscript: all authors.

\section{ORCID iDs}

Ana Karina Lima Buriti https://orcid.org/0000-0001-9504-9795

Daniela Gil https://orcid.org/0000-0002-8647-6813

\section{REFERENCES}

1) Pascual-Leone A, Amedi A, Fregni F, Merabet LB. The plastic human brain cortex. Annu Rev Neurosci 2005;28:377-401.

2) Musiek FE, Shinn J, Hare C. Plasticity, auditory training, and auditory processing disorders. Semin Hear 2002;23:263-75.

3) Cramer SC, Sur M, Dobkin BH, O'Brien C, Sanger TD, Trojanowski JQ, et al. Harnessing neuroplasticity for clinical applications. Brain 2011;134:1591-609.

4) Musiek FE, Chermak G. Testing and treating (C)APD in head injury patients. The Hear J 2008;61:36-8.

5) Saunders GH, Frederick MT, Arnold M, Silverman S, Chisolm TH, Myers P. Auditory difficulties in blast-exposed Veterans with clinically normal Hearing. J Rehabil Res Dev 2015;52:343-60.

6) Vander Werff Kathy R. The application of the international classification of functioning, disability and health to functional auditory consequences of mild traumatic brain injury. Semin Hear 2016;37: 216-32.

7) Bellis TJ, Chermak GD, Ferre JM, Musiek FE, Rosenberg GG, Williams EJ, et al. Central auditory processing disorders. (Practice Portal) [Internet]. Rockville, MD: American Speech-LanguageHearing Association [cited 2018 Oct 10]. Available from: https:// www.asha.org/Practice-Portal/Clinical-Topics/Central-AuditoryProcessing-Disorder/.

8) Musiek FE, Schochat E. Auditory training and central auditory processing disorders: a case study. Semin Hear 1998;19:357-66.

9) Cruz ACA, de Andrade AN, Gil D. Effectiveness of formal auditory training in adults with auditory processing disorder. Rev CEFAC 2013;15:1427-34.

10) Musiek FE, Chermak GD. Diagnosis of (central) auditory processing disorder in traumatic brain injury psychophysical and electrophysiological approaches. ASHA Lead 2009;14:16-9.

11) Chermak GD, Musiek FE. Auditory training: principles and approaches for remediating and managing auditory processing disorders. Semin Hear 2002;23:297-308.

12) Gil D. Formal auditory training for adults with hearing impairments [dissertation]. São Paulo: Federal University of São Paulo 
(UNIFESP);2006.

13) Ávila RRA, Murphy CFB, Schochat E. Effects of auditory training in elderly with mild cognitive impairment. Psicol Reflex Crit 2014; 27:547-55.

14) Batista PB. Acoustically controlled auditory training in patients with type I neurofibromatosis [dissertation]. Belo Horizonte: Federal University of Minas Gerais;2016.

15) Marangoni AT, Suriano ÍC, Buriti AKL, Gil D. Formal auditory training with individuals after traumatic brain injury. Health 2017; 9:975-86.

16) Castan ATM, Luiz CBL, Gil D. Acoustically controlled auditory training in an adult after traumatic brain injury. Rev CEFAC 2017; 19:126-34.

17) Figueiredo CC, Andrade AN, Marangoni-Castan AT, Gil D, Suriano IC. Behavioral and electrophysiological auditory processing measures in traumatic brain injury after acoustically controlled auditory training: a long-term study. Einstein (Sao Paulo) 2015;13; $535-40$.

18) Godoy CCF, Gil D. Stability of behavioral and electrophysiological measures of auditory processing after acoustically controlled auditory training in individuals with traumatic brain injury. Proceedings of the 30th International Audiology Meeting; 2015 April 8-11: Bauru. São Paulo: Brazilian Academy of Audiology; 2015. p. AO050.

19) Fillippini R, Brito NFS, Neves-Lobo IF, Schochat E. Maintenance of auditory abilities after auditory training. Audiol Commun Res 2014;19:112-6.

20) Lloyd LL, Kaplan H. Audiometric interpretation: a manual of basic audiometry. Baltimore (MD): University Park Press;1978. p.16-7,94.

21) Jerger J. Clinical experience with impedance audiometry. Arch Otolaryngol 1970;92:311-24.

22) Pereira LD. Sistema auditivo e desenvolvimento das habilidades auditivas. In: Tratado de Fonoaudiologia (Ferreira LP, Béfi-Lopes
D, Limongi SCO, eds). Tratado de Fonoaudiologia. São Paulo, Brazil: Roca;2004. p.547-52.

23) McPherson DL. Late potentials of the auditory system. San Diego, CA: Singular Publishing Group, Inc;1996.

24) Perez AP, Ziliotto K, Pereira LD. Test-retest of long latency auditory evoked potentials (P300) with pure tone and speech stimuli. Int Arch Otorhinolaryngol 2017;21:134-9.

25) Murphy CFB, Fillippini R, Palma D, Zalcman TE, Lima JP, Schochat E. Auditory training and cognitive functioning in adults with traumatic brain injury. Clinics (Sao Paulo) 2011;66:713-5.

26) Schochat E, Carvalho LZ, Megale RL. Auditory training: ability maintenance assessment. Pró-fono 2002;14:93-8.

27) Quinto SMS, Costa LD, Bertuol B, Oppitz SJ, Garcia MV, Biaggio EPV. Permanence of the effect provided by auditory training in subjects with auditory processing disorder. Mundo Saúde 2017;41: 212-22.

28) Duncan CC, Kosmidis MH, Mirsky AF. Closed-head injury-related information processing deficits: an event-related potential analysis. Int J Psychophysiol 2005;58:133-57.

29) Polich J, Howard L, Starr A. P300 latency correlates with digit span. Psychophysiology 1983;20:665-9.

30) Matas CG, Hataiama NM, Gonçalves IC. Stability of auditory evoked potentials in adults with normal hearing. Rev Soc Bras Fonoaudiol 2011;16:137-41.

31) Ledwidge PS, Molfese DL. Long-term effects of concussion on electrophysiological indices of attention in varsity college athletes: an event-related potential and standardized low-resolution brain electromagnetic tomography approach. J Neurotrauma 2016;33: 2081-90.

32) Segalowitz SJ, Bernstein DM, Lawson S. P300 event-related potential decrements in well-functioning university students with mild head injury. Brain Cogn 2001;45:342-56. 